\title{
Spinal Şıvannomalar: Vaka Serisi ve Literatür Taraması
}

\author{
Halil İbrahim Sun, Necmettin Pamir
}

Acıbadem Üniversitesi, Beyin ve Sinir Cerrahisi, Istanbul, Türkiye

Halil Ibrahim Sun Necmettin Pamir

İletişim:

Halil lbrahim Sun

Acıbadem Üniversitesi, Beyin ve Sinir Cerrahisi, Istanbul, Türkiye

E-Posta: nssun@yahoo.com

Gönderilme Tarihi : 17 Mart 2017

Revizyon Tarihi : 04 Eylül 2017

Kabul Tarihi : 19 Eylül 2017

\section{ÖZET}

Amaç: Şıvannomalar yılda 0.3-0.5/100.000 insidans ile en sık görülen primer omurga tümörleridir. Sendromik olmayan spinal şıvannomalar için güncel tedavi yöntemi tümörün nörovasküler yapılar korunarak total çıkarımıdır. Bu makale, kliniğimizdeki sendromik olmayan spinal şıvannoma vakalarının tedaviden sonraki nörolojik ve radyolojik sonuçlarını rapor etmeyi amaçlamaktadır.

Hastalar ve Yöntemler:Bu retrospektif vaka serisi, sendromik olmayan spinal şıvannomu olan 82 hasta ile yapılmıştır. Hastaların verileri hastane kayıtlarından bulunmuştur. Tümör çıkarım ameliyatı sonrası nörolojik muayene ve kırk beşinci, yüz sekseninci ve üç yüz altmışıncı günlerde takibi yapıımıştır. Karnofsky performans durum değerlendirmesi ışığında; hastaların acı, duyu ve motor zayıfııları nörolojik iyileşmeyi göstermek için puanlandırılmıştır.

Bulgular: Ameliyat öncesinde ve sonrasındaki komplikasyon sadece iki hastada gerçekleşmiştir.

Sonuç: Bulgularımız, sendromik olmayan spinal şıvannomaların total reseksiyonunun, etkin ve güvenilir bir cerrahi girişim olduğunu ortaya koymaktadır.

Anahtar sözcükler: Spinal şıvannomlar, omurga tümörleri, şıvannom

\section{SPINAL SCHWANNOMAS: CASE SERIES AND LITERATURE REVIEW}

ABSTRACT

Objectives: Schwannomas are the most frequently seen primary spinal tumors with a $0.3-0.5 / 100.000$ incidence. For non-syndromic spinal schwannomas, the current treatment modality is a gross total resection with the preservation of neurovascular structures. We aim to show the postoperative neurologic and radiologic findings of our patients with non-syndromic spinal schwannomas.

Patients and Methods: This retrospective case series have 82 patients. Patients were followed up on the 45 th, 180 th and 365th days postoperatively. In the light of Karnofsky performance test, patients have been evaluated for pain, sensory and motor deficits.

Results: Intra and preoperative complications occured only in 2 patients.

Conclusion: Our findings show that total resection of non-syndromic spinal schwannomas is an effective and safe surgical approach.

Keywords: Spinal schwannoma, spinal tumors, schwannoma

ıvannomalar en sık görülen primer omurga tümörleridir. İnsidans oranı 0.3$0.5 / 100.000$ aralığındadır (1). Prevelans kadın erkek dominansisi göstermez ve görülme yaşı, genellikle, 30 ila 40 yaş arasındadır (2). Şıvannomalar lomber ve servikal bölgelerde daha sık görülmekte olup Schwann hücrelerinin öncülerinden orijin alırlar (3). Şıvannomalar genelde selim tümörlerdir ve kapsüllü, yuvarlak, hatları belirgindir. Şıvannomatozis, multipl şıvannoma varlığı durumudur. Şıvannomatozis 
altta yatan bir genetik predispozisyonu, nörofibromatozis gibi, gösterebilir (4). Multipl şıvannomalar, şıvannoma vakalarının \%3 ile \%4'ünü oluşturur (5). Araştırma sonuçları, şıvannomatozis ile şıvannomların genetik ve klinik olarak farklı olduğunu göstermişlerdir (6). Bu yüzden, şıvannomatozis durumu sendromik olmayan şıvannomalardan farklı durumlar olarak tedavi edilmelidir.

Sendromik olmayan spinal şıvannomlu hastalar hastaneye genellikle progresif lokal ağrı ve nörolojik defisitler yüzünden başvururlar. Bu vakalarda tedavi yöntemi nörovasküler yapılar korunarak tümörün total rezeksiyonudur (7). 1888 'de Victor Horsley ilk defa 6 ve 7. torasik vertebralar arasındaki bir spinal tümörü başarıyla çıkartmıştır (8). O vakitten beri; görüntüleme, intraoperatif monitarizasyon ve mikrocerrahideki ilerlemeler total reseksiyonu kolaylaştırmıştır. Ek olarak, literatür taramalarındaki başarı yüzdeleri, detaylı bir güncel tedavi değerlendirmeleri için verilmiştir (9-12).

\section{Hastalar ve yöntemler}

Hastalar

Seksen iki hastanın hepsi 1987-2015 tarihlerinde ameliyat edilmiştir. Hasta bilgileri hastane arşivinden toplanmış olup klinik bulgular, radyolojik bulgular ve ameliyat bulguları olarak sınıflandırılmıştır. Otuz dokuz (47.5\%) kadın ve 43 (52.5\%) erkek hastadan oluşan hasta grubunun yaş aralığı 18 ile 77 yıl arasında değişmekte olup ortalama yaş 45,4 yıldır.

Bilgisayarlı tomografi (BT) ve myelografi, 1990 yılına kadar olan şıvannoma hastalarının teşhisinde kullanıldı. Manyetik rezonans görüntüleme (MRG) 1990'dan sonraki hastalarda kullanıldı. 3 hastada MRG sonuçları olmadığından eski yöntemler ile tümör belirlendi.

\section{Ameliyat}

Hastalar pron pozisyonda posterior yaklaşımla opere edildi. Tümör seviyesi, cilt insizyonundan önce floroskopi ile belirlendi. Cilt orta hattan açıldı ve subperiostal kas disseksiyonu ve retraksiyonu sonrası laminalar ortaya konuldu. Total laminektomi tümörün uzanımına göre bir ila üç seviyeden gerçekleştirildi. Fasetektomi gerektiğinde uygulandı ve tümörün ekstraforaminal kısmı bu şekilde ortaya konuldu. Sonrasında dura açıldı ve tümör ortaya çıkarıldı. Ameliyatlardaki amaç, nörovasküler yapıları koruyarak tümörün tamamının çıkartılması olarak belirlendi. Tümör eksizyonu mikrocerrahi ile yapıldı ve ultrasonik aspiratör enükleasyon için vakaların hepsinde kullanıldı. Bu serideki 57(\%70) hasta, 2000 yılından sonra, somatosensoryel-uyarılmış potansiyeller ile intraoperatif monitorizyon kullanılarak opere edildi. Anatomik yapılar katmanlarına uygun olarak kapatıldı. Hemostaz ajanları ameliyat esnasında kanama kontrolü için kullanıldı.

\section{Takip}

Tümör çıkarımı 79 hastada ilk 24 saat içinde çekilen MRG ile doğrulandı. Üç hasta 1990 öncesi MRG yokluğunda BT ile kontrol edildi. Ameliyattan 45 gün, üç ay ve 1 yıl sonra takipleri yapıldı. Takipler 5 yıl için planlanmış olsa da bu yazıya bir yıllık takipler dahil edildi. İki hasta postoperatif lomber drenaj aldı ve enfeksiyon oluşmadı. Tüm hastalar Klekamp ve Samii tarafından kullanılan sistem ile skorlandı (13). Hastalar acı, duyu bozuklukları, motor güçsüzlükleri için Karnofsky skoru ile skorlandı (Tablo 1).

\section{Bulgular}

Hasta grubumuz 82 sendromik olmayan spinal şıvannomalı hastalardan oluşmaktadır. Total reseksiyon 81 hastada gerçekleştirildi ve tümörün ön kısmının çıkarılması esnasında vertebral arter yaralanması yaşayan bir hastada subtotal reseksiyon gerçekleştirildi. Otuz dört (\%43) şıvannoma servikal bölgede, 17 (\%21) torasik ve 31'i (\%36) lombar bölge tümörü olarak tespit edilmiştir (Tablo 1).

Tablo 1. Serideki şıvannom hastalarının tip ve bölgelere göre dağılımı

\begin{tabular}{cccccc} 
& & $\begin{array}{c}\text { Cervikal } \\
\boldsymbol{n}(\%)\end{array}$ & $\begin{array}{c}\text { Thorakal } \\
\boldsymbol{n}(\%)\end{array}$ & $\begin{array}{c}\text { Lombar } \\
\boldsymbol{n}(\%)\end{array}$ & Toplam \\
\hline Tip I & A & $3(3.6 \%)$ & $4(4.8 \%)$ & $12(14.6 \%)$ & $19(23.1 \%)$ \\
& B & $3(3.6 \%)$ & $8(9.7 \%)$ & $10(12.1 \%)$ & $21(25.6 \%)$ \\
& C & $6(7.3 \%)$ & $4(4.8 \%)$ & - & $10(12.1 \%)$ \\
Tip II & A & $4(4.8 \%)$ & - & $2(2.4 \%)$ & \\
& B & $6(7.3 \%)$ & $1(1.2 \%)$ & $3(3.6 \%)$ & $10(12.1 \%)$ \\
& C & $7(8.5 \%)$ & - & $1(1.2 \%)$ & $8(9.7 \%)$ \\
Tip III & A & - & - & - & - \\
& B & $3(3.6 \%)$ & - & - & $3(3.6 \%)$ \\
& C & $2(2.4 \%)$ & - & $1(1.2 \%)$ & $3(3.6 \%)$ \\
Tip IV & A & - & - & - & - \\
& B & $1(1.2 \%)$ & - & $1(1.2 \%)$ & $2(2.4 \%)$ \\
& C & - & - & - & - \\
TOPLA & & $35(42.6 \%)$ & $17(20.7 \%)$ & $30(36.5 \%)$ & $82(100 \%)$
\end{tabular}

Bir hasta postoperatif yara enfeksiyonu geliştirdi ve bu antibiyotiklerle tedavi edildi. Bir hastanın beyin omurilik sIVISı (BOS) fistülü lombar drenaj ile 5 gün tedavi edildi ve hiçbir komplikasyon olmayarak iyileşti. İki hastanın ameliyat sonrası sağlık durumunda kötüleşme gözlendi ancak 2 hafta içinde tamamen iyileştiler. Tedaviye bağlı hiçbir ölüm gerçekleşmedi. 

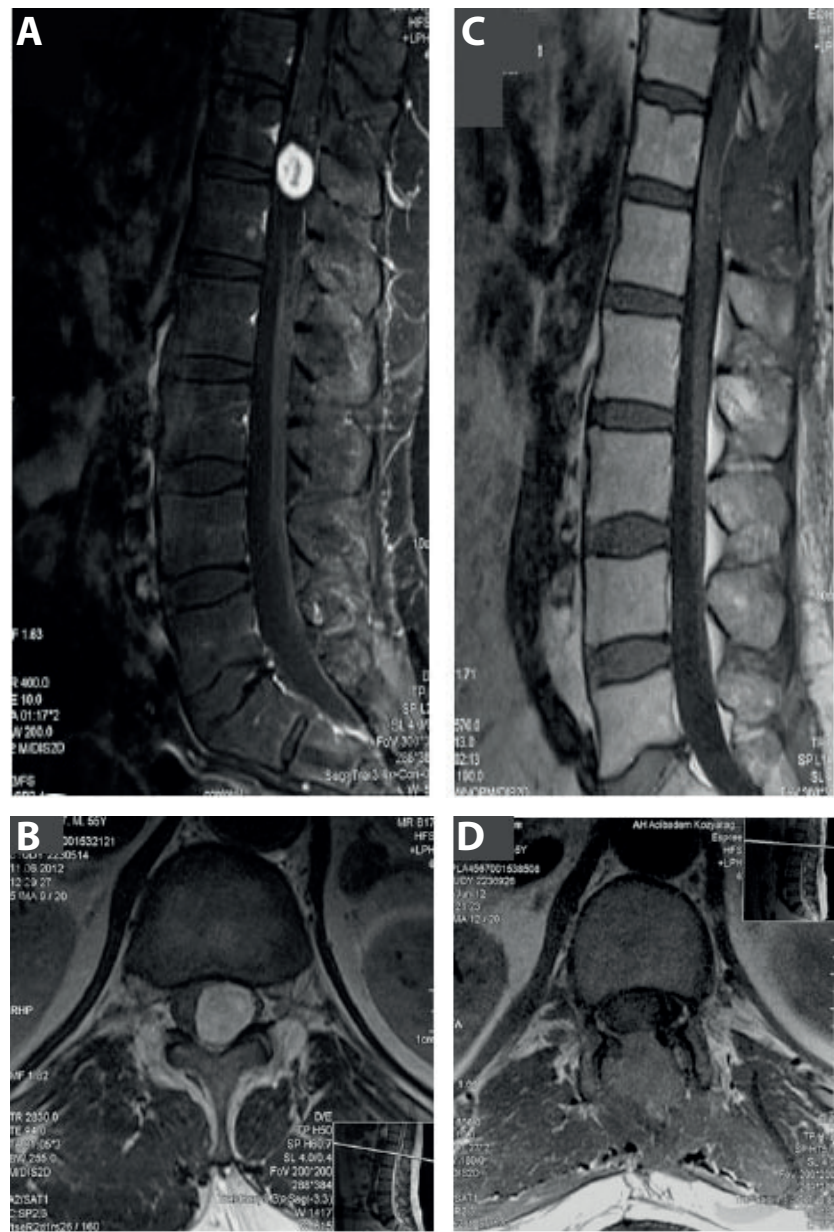

Şekil 1. Tümörün $T 1$ ağırlıklı sagittal kesitten görülüşü $(A, C)$. Tümörün $T 1$ ağırlıklı axial kesitten görünüşü $(B, D)$

\section{Tartışma}

Intradural ekstramedüller tümörler, yaklaşık \%55 ile, en büyük grup primer spinal tümörleri oluştururlar. Bu tümörler çoğunlukla iyi huylulardır ve meninjiyomalar, nörofibromlar ve şıvannomaları içeren sinir kılıfı tümörlerini içerirler. Spinal şıvannomalar yaklaşık olarak en yaygın sinir kılıfı tümörleri olan spinal tümörlerin \%25'ini oluştururlar $(11,3)$.

Spinal şıvannomlar tipik olarak arka duyusal sinir köklerinden ortaya çıkan kapsüllü lezyonlardır. Histolojik olarak şıvannomalar Antoni A olarak adlandırılan füziform, siyah lekeli ve kompakt fasiküllü bir şekle sahip olan elonge bipolar hücrelerden oluşur. Göreceli olarak daha az sıkışık bir biçimde olan yıldız hücreleri Antoni B olarak adlandırılırlar. Mitotik figürler şıvannomalarda nadir olarak görülürler (14). Çoğu şıvannoma ya katı ya da heterojen katı tümörlerdir ancak kistik dejenerasyon, ksantomatöz veya kanama ile değişime uğrayabilirler (15). Bizim serimizde, 10 hastanın kistik komponenti olan tümörü vardı. Ameliyat prosedürü hastanın kisti olup olmamasına göre değişmedi. Önceki çalışmaların gösterdiği üzere spinal şıvannomalar kadın ve erkeklerde eşit oranlarda ve genel olarak 25-50 yaş aralığında görülmektedir (2). Daha önceki raporlarla aynı çizgide olarak, bizim serimizde kadınlarla erkekler arasında bir fark bulunmamasına rağmen, bizim hastalarımız genel olarak hayatlarının 5. ve 6. on yılında bulunmaktaydı. Bir sinir kılıfı tümörü dural kesenin içinde lokalize olabileceği gibi tamamen dışında ya da tümör orijininin lokasyonuna bağlı olarak kısmi içinde ya da spinal sinir köklerinde de bulunabilir. Yayınlanmış makalelere benzer olarak, serimizde şıvannomalar çoğunlukla servikal ve lombar bölgede ve daha düşük frekanslı olarak torasik bölgelerde gözlenmiştir (1). MRG'de, şıvannomalar düzgün sınırlı T1 ağırlıklı sekanslarda hipointens, T2 sekanslarda ise hiperintens olarak görülen değişik miktarda kontrast tutabilen görünümdeydi. MRG, tümörün ekstradural veya intramedüller olmasını ayırt etmede yeterli bir görüntüleme yöntemidir. (15). Spinal şıvannomalar için genel inceleme prosedürü bizim kliniğimizde MRG olarak kabul edilir. Preoperatif inceleme ve rekürans intimaline karşın postoperatif kontrol MRG ile yapılır.

Lokalizasyonuna göre değişim göstermekle birlikte, spinal şıvannomalar genelde sinir kökü ağrısı ve radikülopatiye sebep olurlar. Uyuşukluk, his azalması ve kas gücü azalması semptomlar olarak görülse de bizim 65 hastamızda (\%79) ilk semptom olarak ağrı saptanmıştır. Spinal şıvannomlar başlıca sinirlerin duyusal divizyonundan ortaya çıkmaktadır. Bu bağlamda bu bilgi ve datamız SD skorunun istatistik anlamlılık değişim göstermemesi sonucuyla uyumludur. Postoperatif skorlarla kıyaslandığında postoperatif birinci gün KS skorları da herhangi bir şıvannoma hastasında istatistik değişiklik göstermedi. Ancak postoperatif 1. yıl sonuçları bütün tiplerde signifikatif bir gelişim ortaya çıkarmıştır.

Şıvannomalar muhtemel olarak bir sinir fasikülünden ortaya çıkarlar ve infiltre etmek yerine komşu sinir iğciklerinin yerine geçerler. Fonksiyonel öneme sahip sinir kökünü korumaya çalışmamak pahasına total çıkarım tercihi hala cerrahlar için kritik bir karar niteliğindedir. Kim ve diğerleri fonksiyonel öneme sahip sinir köklerini (C5-T1 or L3-S1) total çıkarım için feda ettikleri 31 vaka yayınladılar. Nörolojik defisit oranı \%23 olmasına rağmen hiçbir vakada bu defisit zayıflatıcı bir şekilde sonuçlanmadı (12). Bizim hastalarımızda şıvannomadan etkilenmiş sinirlerin eksizyonu sonrası hiçbir ek sinir defisiti gözlemlenmedi. 
Spinal sinir kllıf tümörlerinin büyük çoğunluğu (\%90>) iyi huyludur. Sarkomatöz dejenerasyon, nörofibromatozü olan hastaların çoğunluğunda görülür (15). Moleküler ve genetik çalışmalar göstermiştir ki şıvannomatozis belirgin bir genetik ve klinik bir sendromdur (16). Dolayısıyla, nörofibromatozisi olan şıvannomatozis hastaları bu çalışmadan çıkarılmıştır. Spinal şıvannomalar tekil, küçük, iyi huylu lezyonlardır ve çıkarma işlemleri görece kolay kabul edilir. Total çıkarım sonrasında prognozları iyi kabul edilir. Spinal şıvannomalı hastaların ölüm oranları çok düşüktür ve yaşam süresi beklentileri normal genel popülasyonla aynıdır (3). Çoklu şıvannomaların idaresi çoğunlukla tekil olanlarınkinden daha komplekstir (4). Retroperitoneal lokalize olmuş şıvannomalar nadir görülür ve şıvannomaların \%3'üne tekabül etmektedir (8). Bizim serimiz retroperitoneal lokalize olmuş şıvannomlu bir hasta içermektedir.

Bizim sonuçlarımız ve literatürdeki sonuçlarını içeren bir kıyaslama sunmak amacıyla raporlanmış şıvannoma vakalarını içeren bir literatür taraması yaptık. 1992 ve 2016 yılları arasında yayınlanmış olan 25 çalışmaya dahil ettiğimiz bu taramamızın sonuçları dahilinde, bizim çalışmamızı da içine katarak 2412 şıvannoma vakasını tespit ettik (Tablo 2). Genel olarak, çalışma başına sunulan vaka sayısı medyanı 44 olarak bulundu. Cinsiyet bilgisi bütün vakalar için ulaşılabilirdi; $1247(\% 51,69)$ erkek ve $1165(\% 48,31)$ kadın hasta. Ortalama yaş 45.-,6 olarak tespit edildi. Spinal aks üzerindeki tümör lokalizasyonu bilgisi de bütün vakalar için mevcuttu: $\% 33,92$ servikal, $\% 28,4$ torasik ve $\% 37,68$ lumbosakral. Cerrahi çıkarım sonuçları 2405 vaka için, total çıkarım oranı \%93'tü. Fonksiyonel ve nörolojik sonuçlar 2138 hasta için rapor edilmiş, \%79,84'i gelişme gösterirken, \%14,4'i aynı kalmış ve \%5,76'sıysa kötüye gitmiştir.

Ameliyat sonrası nörolojik sonuçlar çalışmadan çalışmaya değişkenlik göstermesi, çalışmalar arasında kıyaslama yapmayı zorlaştırmıştır. Yine de ameliyat sonrası kötüleşen hastaların oranı, ameliyat başarı oranı için güvenilir

\section{Kaynaklar}

1. Seppala MT, Haltia MJ, Sankila RJ, Jaaskelainen JE, Heiskanen O. Long-term outcome after removal of spinal schwannoma: a clinicopathological study of 187 cases. J Neurosurg 1995; 83:621-6. [CrossRef]

2. Jinnai T, Koyama T. Clinical characteristics of spinal nerve sheath tumors: analysis of 149 cases. Neurosurgery 2005; 56:510-5.

3. Safavi-Abbasi S, Senoglu M, Theodore N, Workman RK, Gharabaghi A, Feiz-Erfan l, et al. Microsurgical management of spinal schwannomas: evaluation of 128 cases. J Neurosurg Spine 2008; 9:40-7. [CrossRef]

4. MacCollin M, Chiocca EA, Evans DG, Friedman JM, Horvitz R, Jaramillo D, et al. Diagnostic criteria for schwannomatosis. Neurology 2005; 64:1838-45. [CrossRef]
Tablo 2. Kendi araştırmamız dahil 2412 sendromik olmayan şıvannom

vakasının genel özellikleri

1992 - 2016 Yılları Arasında Raporlanmış Şıvannoma Vakaları $(N=2412)$

\begin{tabular}{lcc}
\hline Cinsiyet & Hasta Sayısı & Yüzde \\
\hline Male & 1247 & $51.69 \%$ \\
Female & 1165 & $48.31 \%$
\end{tabular}

Ortalama Tanı Yaşı $\quad 45.6$

Tümör Lokasyonu Raporlanan tümörlerin Sayısı Yüzde

\begin{tabular}{lll}
\hline Servikal & 822 & $33.92 \%$
\end{tabular}

Thorasik $688 \quad 28.39 \%$

Lumbosakral $\quad 913 \quad 37.68 \%$

Tümörün Tamamının $\quad 2310 \quad 93,00 \%$

Çıkarılması

\begin{tabular}{lcc} 
Sonuç & Hasta Sayısı & Yüzde \\
\hline Daha İyi & 1707 & $79.84 \%$ \\
Aynı & 308 & $14.40 \%$ \\
Daha Kötü & 123 & $5.75 \%$
\end{tabular}

bir ölçüt sağlayabilir. 1992'den 2015'e kadar olan raporlar yaklaşık olarak hastaların \%5,75'inin kötüleşme yaşadığını göstermektedir. Bizim serimizdeyse postoperatif kötüleşme oranı (ki bu oran aynı zamanda komplikasyon oranıdır) literatürdeki oranın bir şekilde altında, $\% 1,2$ oranındadır. Ameliyat odasında uygulanacak en iyi yöntemleri belirlemek ve standardize etmek cerrahlar için bir meydan okuma olarak görülür. Ameliyat öncesi planlama bu noktada cerrahi komplikasyonları azaltmada çok önemli bir rol oynar.

Serilerimizden çıkan bulgular, sendromik olmayan spinal şıvannomalar için total reseksiyonun etkililiğini ve güvenliğini ortaya koymaktadır. Spinal şıvannomalar operasyon öncesi ve sonrası MRG ile incelenmeli ve değerlendirilmelidir.

5. Gottfried ON, Binning MJ, Schmidt MH. Surgical approaches to Spinal Schwannomas. Contemporary Neurosurgery 2005; 27:1-9.

6. Javalkar VK, Pigott T, Pal P, Findlay G. Multiple schwannomas: report of two cases. Eur Spine J 2007;16: 287-92. [CrossRef]

7. Asazuma T, Toyama Y, Maruiwa H, Fujimura Y, Hirabayashi K. Surgical strategy for cervical dumbbell tumors based on a three-dimensional classification. Spine 2004; 29: E10-4. [CrossRef]

8. Cury J, Coelho RF, Srougi M. Retroperitoneal schwannoma: case series and literature review. Clinics 2007; 62:359-62.

9. Chowdhury FH, Haque MR, Sarker MH. High cervical spinal schwannoma; microneurosurgical management: an experience of 15 cases. Acta Neurol Taiwan 2013; 22:59-66. 
10. Fernandes RL, Lynch JC, Welling L, Gonçalevs M, Tragante R, Pereira C. Complete removal of the spinal nerve sheath tumors. Surgical technics and results from a series of 30 patients. Arq Neuropsiquiatr 2014; 72:312-7.

11. Iwasaki Y, Hida K, Koyanagi I, Yoshimoto T, Abe H. Anterior approach for dumbbell type cervical neurinoma. Neurol Med Chir 1999;39:835-9.

12. Kim P, Ebersold MJ, Onofrio BM, Quast LM. Surgery of spinal nerve schwannoma. Risk of neurological deficit after resection of involved root. J Neurosurg 1989; 71:810-4. [CrossRef]
13. Klekamp J, Samii M. Introduction of a score system for the clinical evaluation of patients with spinal processes. Acta Neurochir 1993;123:221-3.

14. Parmar H, Patkar D, Gadani S, Shah J. Cystic lumbar nerve sheath tumours: MRI features in five patients. Australas Radiol 2001;45:123-7.

15. Sridhar K, Ramamurthi R, Vasudevan MC, Ramamurthi B. Giant invasive spinal schwannomas: definition and surgical management. J Neurosurg 2001; 94:210-5.

16. Seppala MT, Haltia MJ. Spinal malignant nerve-sheath tumor or cellular schwannoma? A striking difference in prognosis. J Neurosurg 1993; 79:528-32. [CrossRef] 